\title{
The Problems and Measures of New Growth Pole in the Northwest Region of China
}

\author{
Liang Hua ${ }^{1}$ Zhao Yong $^{2}$ Yuan $\mathrm{Wei}^{3}$ \\ ${ }^{1}$ Shaanxi Academy of Governance, Xi'an shaanxi, China. \\ ${ }^{2}$ Institute of Urban and Environmental Studies, CASS, Beijing, China. \\ ${ }^{3}$ Sichuan Administration Institute, Chengdu, China. \\ Correspondence: Liang Hua, Shaanxi Academy of Governance, Xi'an shaanxi, China.
}

Received: February 24, 2016

Accepted: March 11, 2016

Available online: March 17, 2016

doi:10.11114/aef.v3i2.1470

URL: http://dx.doi.org/10.11114/aef.v3i2.1470

\begin{abstract}
The cultivation of new growth poles in northwest region is very important for the western development strategy, and also necessary for the construction of the Silk Road Economic Belt, the regional coordinated development and rapid economy growth. However, there are some problems, such as small scale, unreasonable economic structure, weak radiation belt power and weak economic relation, and lack of the leading sector. The key point is to expand the total and scale by accelerating the development of core city, enlarge the capability of Industry support by cultivating characteristic and advantage industry, promote the innovative development by regional integration and regional cooperation, enforce the link by promoting the functional division, Optimize environment by enforcing regional Unicom and development environment, and accelerate development by informatization.
\end{abstract}

Keywords: Northwest Region, new growth poles, Problems, Measures

\section{Introduction}

\subsection{Development Status of "New Growth Pole " in Northwest China}

Development economics think that generally growth pole of the formation requires four conditions: there must have a number of innovative companies and entrepreneurs, must have economies of scale, the radiation of core city can stronger drive around the city, and core city and external economic links between each other more closely, and a good investment environment and the production environment (Guo Xi Bao, 2011). In other words, the main growth poles screening choose from four areas, for example, innovation and pilot departments growth, economies of scale, economic structure, radiating of the core city as well as economic ties between cities.

From Northwest history and reality, the subject and the impact of geographical conditions, resource endowments and ecological environment and many other factors, there is little areas can be focus on development or large-scale construction. Economic geographic distribution generally concentrated in the provincial capital cities and its surrounding areas, city traffic arteries, resource and energy-rich regions. Accordance with the general criteria for development economics of growth pole formation, growth poles in northwest regional meets the above conditions mainly in Xi'an, Yinchuan, Lanzhou, Xining, Urumqi, and the capital city is the core of the Guanzhong area, along the Yellow River in Ningxia region, Lancey area, Tianshan Mountains region, and these areas are the best conditions in foundations and the level of development in the Northwest Regional. From the current development of growth pole in Northwest, the main show the following characteristics:

\subsection{The economy weight is relatively large but the development are significant different.}

Four growth poles in Guanzhong area, along the Yellow River in Ningxia region, Lancey area, Tianshan Mountains region are accounted for more than half of the Northwest Territories in population, GDP, fixed assets investment scale, etc. In 2011, resident population of the four growth poles are about 58,030,000 people, in the northwest region accounted for 59.7\%; GDP 1.7926 trillion yuan, accounting for $64.3 \%$ in the Northwest Territories; fixed asset investment 1.1695 trillion yuan, accounting for $55.4 \%$ in the Northwest Territories; local financial revenue reached 129.7 billion yuan, accounted $42.6 \%$ in the northwest region (Table 1). 
Table 1. Northwest Four growth poles economies scale in 2011

\begin{tabular}{|c|c|c|c|c|}
\hline & Unit & $\begin{array}{l}\text { Four growth } \\
\text { poles }\end{array}$ & $\begin{array}{l}\text { Northwest } \\
\text { Territories }\end{array}$ & $\begin{array}{l}\text { Proportion of } \\
\text { four growth } \\
\text { poles } \\
\text { northwest }\end{array}$ \\
\hline permanent residents & Ten thousand people & 5803 & 9723 & $59.68 \%$ \\
\hline GDP & hundred million yuan & 17926 & 27915 & $64.22 \%$ \\
\hline Fixed asset investment & hundred million yuan & 11695 & 21109 & $55.40 \%$ \\
\hline Local fiscal revenue & hundred million yuan & 1297 & 3042 & $42.64 \%$ \\
\hline
\end{tabular}

Source: Calculated from "China Regional Economic Statistical Yearbook (2012)"

However, the development of differences between the various growth poles is great. In 2011, the Guanzhong area resident population reached 2890 million, accounting for the growth in the four poles is $49.8 \%$, about 5.8 times along the Yellow River in Ningxia region, 2.4 times the Tianshan Mountains and Lanxi areas. Guanzhong area GDP reached 838.2 billion yuan, accounting for the growth in the four poles is $46.8 \%$, about 4.5 times the Yellow River in Ningxia region, 2.9 times Lancey areas; Guanzhong area in fixed assets investment reached 710 billion yuan, the proportion of the four growth poles is $60.7 \%$, other areas are less than 200 billion yuan; Guanzhong area local fiscal revenue 52.7 billion yuan, accounting for the growth in the four pole is $42.6 \%$, about 3.4 times the region along the Yellow River in Ningxia, 3.2 times Lancey region (Table 2).

Table 2. Comparison of four growth poles in the northwest region of China in 2011

\begin{tabular}{llccccc}
\hline & Unit & $\begin{array}{l}\text { Guanzhong } \\
\text { area }\end{array}$ & $\begin{array}{l}\text { Tianshan } \\
\text { Mountains }\end{array}$ & $\begin{array}{l}\text { Along } \\
\text { Yellow River in } \\
\text { Ningxia }\end{array}$ & $\begin{array}{c}\text { the } \\
\text { Lancey }\end{array}$ & $\begin{array}{l}\text { Guanzhong } \\
\text { proportion in } \\
\text { growth poles }\end{array}$ \\
\hline permanent residents & 10000 people & 2890 & 1199.6 & 514.8 & 1197.6 & $59.68 \%$ \\
GDP & billion yuan & 8382 & 4874 & 1848 & 2822 & $64.22 \%$ \\
Fixed asset investment & billion yuan & 7100 & 1021 & 1498 & 2076 & $55.40 \%$ \\
Local fiscal revenue & billion yuan & 527 & 447 & 157 & 166 & $42.64 \%$ \\
\hline
\end{tabular}

Source: Calculated from "China Regional Economic Statistical Yearbook (2012)

1.3 Modern industrial system has taken shape but the traditional energy industry account for a higher proportion.

Guanzhong area has obvious advantages in location and traffic conditions, and a better highway, railway, aviation and other infrastructure. It is the most powerful integrated region in northwest of China and has formed of a modern industrial system in advanced equipment manufacturing, electronic information, aerospace, new materials, biotechnology, information technology etc.. Coal, oil, natural gas, salt, nonferrous metals and other energy and mineral resources is extremely rich reserves in Lancey area, Tianshan Mountains region and along the Yellow River in Ningxia, and there are important hundred million tons of large-scale coal bases and large coal million kilowatts base location. Relying on energy and resources, these regions have formed the energy, chemical, metallurgy and other mainly of industrial structure. For example, chemical, ferrous metals, nonferrous metals, oil processing and other industries in the proportion of industrial added value reached 53.3\% in areas along the Yellow River in Ningxia. And added value of oil and gas, oil processing, ferrous metal smelting, chemicals and other industries have reached $57 \%$ in Tianshan Mountains region.

\subsection{The high level of industrialization and urbanization, but population density and space efficiency are quite different.}

In 2011, the four major growth poles industrial output value reached 2.0732 trillion yuan, the average industrial rate reached 51.1\%; total urban population reached 2819.1 million, urbanization rate reached $50.35 \%$, the population density is 162.55 persons / square kilometer (Table 3 ). Among them,the secondary industry of Guanzhong, Tianshan Mountains, Ningxia, Lancey area accounted for the proportion of the province was $44.7 \%, 78.2 \%, 95.1 \%, 41 \%$, and total industrial output value of the province where the proportion was $45.1 \%, 78.2 \%, 99.2 \%, 46.4 \%$; The rate of urbanization in Guanzhong, Ningxia, Lancy region where the provinces are 1.05,1.07,1.04 times the average urbanization rate. 
Table 3. Industrialization and urbanization situations of four growth poles in 2011

\begin{tabular}{|c|c|c|c|c|c|}
\hline area & $\begin{array}{l}\text { Industrial output } \\
\text { (billion yuan) }\end{array}$ & Industrialization rate $(\%)$ & $\begin{array}{l}\text { urban population } \\
\text { (10000 people) }\end{array}$ & $\begin{array}{l}\text { Urbanization Rate } \\
(\%)\end{array}$ & $\begin{array}{l}\text { Population } \\
\text { density (people/ } \\
\text { sq km) }\end{array}$ \\
\hline four & & & & & \\
\hline $\begin{array}{l}\text { growth } \\
\text { poles }\end{array}$ & 20732 & 51.1 & 2819.1 & 50.35 & 162.55 \\
\hline
\end{tabular}

Source: Calculated from "China Regional Economic Statistical Yearbook (2012)"

However, there is a big difference in the four major growth poles between population density and space efficiency. Guanzhong area population density is 323.8 persons / sq km, 1.99 times of the average population density of 4 growth poles, and 13 times the area of the northern slope of the Tianshan Mountains which has the lowest population density. Guanzhong area GDP have reached 9.39 million yuan / square kilometers, respectively is the northern slope of Tianshan Mountains, Ningxia along the yellow and blue in the west area of 9.3, 2.1 and 2.3 times.

\subsection{Science and technology resources are abundant but mainly concentrated in the Guanzhong area.}

The four major growth poles gather the main science and technology education resources in the northwest, while in the four growth poles and mainly focus on Xi'an as the center of the Guanzhong area. Xi'an is the core of Guanzhong area which is one of the most intensive areas of science and education resources in China. There are more than about 100 colleges and universities, and more than 1000 scientific research institutions, more than 100 million science and technology personnel, many science and Technology Park and high-tech industrial park, and there has strong enterprise innovation and R \& D capability, and greater proportion of output in electronic information, new generation information technology, high-end equipment manufacturing and other department of guide and strategic emerging industry innovation.

\subsection{Infrastructure and development environment is constantly improving.}

With the further implementation of the western development strategy, the Northwest regional transport infrastructure network further expand the scale, and the system is more fulfilled, that connecting the major cities of highway, railway, aviation and other integrated transportation system, especially high-speed railway from Zhengzhou to Xi'an, Lanzhou to Urumqi, Lhasa to Shigatse, and transport infrastructure in major cities of Northwest more convenient. Meanwhile, construction speed and coverage have been greatly improved, for example, fixed telephone, mobile communications, optical fiber, Internet broadband and other postal communications and information infrastructure. the number of mobile phone users and broadband internet users of four growth poles have accounted for more than $50 \%$ of their provinces (Table 4).

Table 4. Four growth poles information situation of northwest China in 2011

\begin{tabular}{|c|c|c|c|c|}
\hline & $\begin{array}{l}\text { Number of } \\
\text { mobile phone } \\
\text { subscribers } \\
(10000)\end{array}$ & $\begin{array}{l}\text { Number of mobile } \\
\text { phone subscribers } \\
\text { accounted for the } \\
\text { proportion of the } \\
\text { province }(\%)\end{array}$ & $\begin{array}{l}\text { Internet broadband } \\
\text { access subscribers } \\
\text { (10000 households) }\end{array}$ & $\begin{array}{l}\text { Internet broadband access } \\
\text { users accounted for the } \\
\text { proportion of the province } \\
(\%)\end{array}$ \\
\hline Guanzhong & 2254.7 & 71 & 310.6 & 77 \\
\hline $\begin{array}{l}\text { Tianshan } \\
\text { Mountains }\end{array}$ & 1041 & 52 & 150.1 & 57 \\
\hline $\begin{array}{l}\text { Ningxia } \\
\text { Yellow River }\end{array}$ & 474.7 & 86 & 51.5 & 93 \\
\hline Lancey & 872.6 & 58 & 98.8 & 76 \\
\hline
\end{tabular}

Source: Calculated from "China Regional Economic Statistical Yearbook (2012)

\section{Development issues of" new growth pole" in China's northwest regional}

With the in-depth implementation of the economic development and the strategy of developing the western region, the northwest region of new growth poles realize the fast development, but comparison with the eastern region mature growth electrode, there are still some gaps, and in the national strategic level, as a the role and functions of the growth 
poles is still somewhat inadequate.

\subsection{The Economy is Small And the Scale Effect is Insufficient.}

Although the Guanzhong area, along the Yellow River in Ningxia region, Lancey area, Tianshan Mountains region is the largest economy of several key development areas of the Northwest, but very few compared with the growth in eastern and central regions, economic output is still relatively small. In 2011, northwest maximum economy of Guanzhong Tianshui area is only $10.2 \%$ of the economic gross in the Yangtze River Delta, $19.2 \%$ of the Pearl River Delta area, and $17.8 \%$ of Beijing Tianjin Hebei region. The northwest region of Ningxia is the smallest along the Yellow River, only 2.3\% of the total economic output in the Yangtze River Delta region, 4.3\% in the Pearl River Delta region, $3.9 \%$ in Beijing, Tianjin and Hebei region (Figure 1). The size of the economy is the main problem that restricts the country's strategy and the growth poles in the true sense.

Figure 1. GDP major areas of growth poles in China

\begin{tabular}{|c|c|c|c|c|c|c|c|c|}
\hline & \multirow[b]{2}{*}{ Guanzhong } & \multirow[b]{2}{*}{$\begin{array}{l}\text { Tianshan } \\
\text { Mountains }\end{array}$} & \multirow{2}{*}{$\begin{array}{l}\text { Ningxia } \\
\text { Yellow } \\
\text { River }\end{array}$} & \multirow[b]{2}{*}{ Lancey } & \multirow[b]{2}{*}{$\begin{array}{l}\text { yangtze } \\
\text { river delta }\end{array}$} & \multirow{2}{*}{$\begin{array}{l}\text { The pearl } \\
\text { river delta } \\
\text { region }\end{array}$} & Beijing Tianjin & \multirow[b]{2}{*}{$\begin{array}{l}\text { Shandons } \\
\text { Peninsula }\end{array}$} \\
\hline & & & & & & & $\begin{array}{l}\text { and Hebei } \\
\text { Region }\end{array}$ & \\
\hline $\begin{array}{l}\text { Units } \\
\text { (million) }\end{array}$ & 8382 & 4874 & 1848 & 2822 & 82099 & 43721 & 47024 & 28752 \\
\hline
\end{tabular}

Source: Calculated from "China Regional Economic Statistical Yearbook (2012)"

\subsection{The economic structure is not reasonable, and the urban agglomeration effect is low.}

Due to resource endowments, ownership structure and other reasons, the second industry in the northwest region is relatively high, the development of the third industry is relatively backward, especially the production of the service industry in the third industry. In addition to the Guanzhong area formed a relatively comprehensive modern industrial system, and mainly industry of along the Yellow River in Ningxia region, Lancey area, Tianshan Mountains region is still mining, nonferrous metals, energy, equipment manufacturing and other industries, and the proportion of high-tech industries and producer services is still low. Meanwhile, the low level of economic development, backward social system reform and related urban construction system, the level of urbanization in these areas is lower than the overall growth in the eastern china. In addition, restricted by location situation, industry structure and level of economic development, except relatively high Tianshan Mountains region, other regional growth poles in northwest remains significantly lower than the growth in eastern, even lower than the Southwest Chengdu-Chongqing region in opening-up level.

\subsection{Lack of power in the core cities, the economic ties between cities is weak.}

The population and economic activities of the growth pole core cities in the northwest region are relatively low, the economic scale is small, and the driving effect on the surrounding cities is limited. Except Xi'an, urban core population size of northwest area was less than 500 million, and GDP were lower than 50 billion yuan, was significantly lower than that growth poles in the central regions of eastern city, and even far lower than the south-west of Chengdu and Chongqing. At the same time, restricted by low degree of the market development, local government competition in the homogenization and adminis trative barriers etc, Market segmentation degree is higher, the economic ties are weak, and the core city's radiation belt power and peripheral cities supporting capacity are weak in Northwest China growth poles between the core city and surroundings.

In addition, with resources and heavy industry industrial structure which Leading industry chain is short, the industry to contact is weak, the industrial division of labor and cooperation between cities is not close in the region along the Yellow River in Ningxia, Lancey area, Tianshan area. Although the economy is relatively developed and the industrial system is relatively good in guanzhong region, the characteristics of homogeneous development is obvious, and the division of labor and economic ties between cities is obviously weaker than that of the eastern region. In 2011, spatial division of function in the Guanzhong Tianshui area is 2.02, significantly lower than the Yangtze River Delta, Pearl River Delta area and Beijing Tianjin Hebei region, is also lower than the central and southern Liaoning Province and Shandong peninsula area (Figure 2). 
Figure 2. Spatial functional division of China's major growth poles

\begin{tabular}{llllllll}
\hline $\begin{array}{l}\text { Beijing } \\
\text { Tianjin } \\
\text { Hebei }\end{array}$ & $\begin{array}{l}\text { Central } \\
\text { southern } \\
\text { Liaoning } \\
\text { Province }\end{array}$ & and & $\begin{array}{l}\text { Yangtze River } \\
\text { Delta }\end{array}$ & $\begin{array}{l}\text { Shandong } \\
\text { Peninsula }\end{array}$ & $\begin{array}{l}\text { Pearl } \\
\text { Delta }\end{array}$ & River & Guanzhong \\
\hline 2.98 & 2.37 & 3.08 & 2.38 & 3.03 & 2.02 \\
\hline
\end{tabular}

Source: the author calculated. (Calculation method: According to the ratio of "productive service employees / Manufacturing employees" and peripheral cities "productive service employees / Manufacturing employees" to measure function and space division level of central city growth poles.)

\subsection{Innovation ability is low and the growth of the pilot sector is insufficient.}

Because of factors of human capital, research and development, industrial structure and the development of other aspects of the environment, technological innovation capability of northwest is overall weak and has low pilot sector growth.Even in Guanzhong area, the innovation elements and human capital are more intensive, research institutions and related factors focused on the military and the large state-owned enterprises. Restriction of ownership and scientific research management system, there are" two pieces of skins" phenomenon between central research institutes and local economic development, scientific research activities and economic development, state-owned large and medium-sized enterprise technology research and development.(yongxiu,bai; 2010) Fusion technology research and development and the conversion between applications, lower integration between military and civilian inter-industry affect the technical contact, department, industry contacts, and these make the role of research and development, innovation and human capital on economic growth is restricted. These factors led to the growth of the northwest region is far lower than the growth pole of the eastern region, the pilot sector and the growth of the industry is limited, which restricts the growth pole of innovation and leading role of radiation.

\section{Cultivating Measures of "new growth poles" in Northwest China}

Based on development Status and Problems of the new "growth pole" in Northwest, the new "growth pole" in the northwest region of China need to be focused and layered to cultivate.

\subsection{Northwest China accelerates the development of the core city to promote the economies expansion of scale growth} pole.

Its economic growth pole needs further scale to achieve total expansion by implementation of cluster development strategy to further strengthen the economic growth and leading role of the core cities, for example, the development of the urban road traffic infrastructure, public services, industrial parks, urban construction district, and continuously improve the business environment, and all these further improve the population agglomeration and industrial development ability, and attract population and economic activities to the growth poles which improve economies scale and the leading role of the core city. By promoting population management, land management, tax and finance, urban housing, administration, environment and other key aspects reforms, especially with the reform of the household registration system, northwest region needs innovation and improve population service and management system to promote the population flow orderly, equitable distribution and social integration to achieve stable agricultural population transfer to major growth pole regions, as well as labor mobility between the growth poles.

\subsection{Northwest cultivate special industries to improve their ability to support industrial growth poles.}

With the stage transformation of the China's economic growth, the northwest region growth poles change from elements driven strategy to efficiency drive strategy, and improve the efficiency of resource allocation and utilization efficiency to enhance regional capacity for independent development, by combination the technological innovation, information transformation and management to enhance the superior industries. To improve the endogenous development momentum as the main line, northwest enhance the traditional advantages of the industry. Western Region deepens advantageous resources transformation to extend the industrial chain and increase value-added products and improve the level of deep processing of resource products. With high technology and advanced applicable technologies to transform and enhance traditional industries, northwest improve the characteristics and advantages of the industry technology and equipment level and product competitiveness, and promote industrial upgrading, consolidate, expand, enhance energy, chemical industry, mineral processing and agricultural and animal husbandry products processing and other traditional resource-based characteristics and advantages industry. As the support of Technological innovation and system innovation, the western region vigorously develops the modern characteristics and advantages industry. To enhance the capability of independent innovation and transformation advantage of the resources depth, the western region give full play to the advantages of Xi'an scientific and technological resources, and develop high-end equipment 
manufacturing, aerospace and electronic information, new materials, renewable energy, focusing on emerging industries to promoting industrial Upgrade. Western Region improve the industrial supporting capacity and accelerate the development of producer services, and strive to improve the level of modern production and the proportion of the service industry, and promote the transformation of the manufacturing industry to production and service, to achieve industrial integration and development. The western region promotes industrial upgrading, and actively undertakes industrial transfer. Through reasonable choice of industrial undertake direction and optimization to undertake industrial transfer field and structure, they take fill chain to undertake with a high standard environmental protection to undertake equipment manufacturing, energy and raw materials, high-tech, modern service industry, agriculture and animal husbandry products processing industry and modern service industry to enhance the level of development in northwest growth poles.

\subsection{Northwest promote growth pole innovative development by regional integration and regional cooperation.}

on the basis of expanding open up both internally and externally, northwest should further strengthen the cooperative development mode, and improve cooperation mechanisms in the field of resource development, industrial investment, technology exchange, market development, education and training, environmental protection, etc., and also deepen regional Cooperation. Northwest combines the industrial development and industries to relocate to the west and open the geographical advantages, and rely on the "Silk Road Economic Belt" construction, and deepen the Northwest and East Midlands and economic cooperation of neighboring countries, and build a new growth pole northwest of internal and external the new pattern of regional cooperation. With the advantage of talent, capital, technology, management and investment experience in eastern, as well as attract foreign investors to explore cooperation to build a platform for cooperation between the eastern industrial park, free trade area of the Silk Road Economic Belt. Northwest region should innovative industrial park development model and management mechanism to encourage the eastern region directly involved in the development, construction and operation of the park management cooperation to achieve common construction and benefit-sharing. Play demonstration leading role of Yinchuan, Ningxia, Gansu LAN white economic zone, and continue to promote the new growth pole in northwest region, especially center city, resource rich zones and key border city to undertake industrial transfer of demonstration zone construction. It actively support the new eco-industrial park, eco-industrial park German, EU cooperation demonstration zone industrial parks located in the Northwest Territories. Northwest especially in Xinjiang, Ningxia west will make full use of regional advantages and cultural advantages, expand the depth of cooperation with neighboring countries in the areas of investment, industry, technology, trade and the like. Actively develop export-oriented processing base and logistics center with Russia and Mongolia, Central Asia, the Arab States and Europe, and promote border (cross-border) economic cooperation zones, border free trade zone, EU cooperation demonstration zone, CEFTA, China - central Asian cooperation demonstration zone, China - Arab demonstration platform for building regional cooperation in energy cooperation between China and Russia and Mongolia demonstration area, to strengthen ties with the European Union, ASEAN, the Arab countries and other international central market, and promote the development of the growth poles in Northwest region (Wei Houkai, 2015).

\subsection{Northwest improve economic ties of growth poles through the core function division of urban space and surrounding} cities.

From the region of growth poles, according to the spatial pattern of the division of functions, and continuously improve the efficiency of space allocation feature is the focus of future development of growth poles. Northwest region adapt to the regional division of labor and cooperation to share the development of new trends, and reshape the growth of the concept of development. In accordance with the principle of the functions division and collaborative sharing, it change the concept of the city by the urban cluster development ideas into the concept of individual development alone, and change the concept of competition from a single city to city cooperation, from urban hierarchy development to flattening cooperation, from the geographical link to the functional link, from boundaries to the development of no boundary. Urban agglomeration economies play a synergistic role in enhancing allocation efficiency of features and spaces. These Guide the urban core re positioning function, continuous improve the urban environment and supporting services, attract high skilled workers gather, vigorously develop the productive service industry and realize the transition from factor driven to innovation driven; small and medium-sized cities should play the advantages of low cost, and actively undertake the transfer of manufacturing industry, Mainly located in the core city services and support. Northwest strengthen the docking and collaboration from core to the periphery of urban city industrial transfer, through the comprehensive analysis factor endowment structure, leading industry and industry chain characteristics, technology absorptive capacity, supporting facilities and so on. Growth Poles undertake the industrial park as chain of transfer platform, along the lines of the industry chain cooperation to undertake the core business as the focus of investment, and the development of related enterprises to enter the industry to improve the efficiency of the transfer process and elements of docking space reallocation efficiency. 
3.5Northwest Region optimizes the development environment of the growth poles by the regional Unicom and the development environment.

The formation and development of growth poles can not be separated from good infrastructure and development environment. Northwest China should speed up the interconnection of infrastructure between internal growth poles and different growth poles. For extremely low level of road and rail density in new growth poles of Northwest, road network synergy is not high, it should further improve the transportation infrastructure level, and optimize transportation infrastructure connectivity route planning and layout, and accelerate the intercity rapid rail transit passage, highways and the like construction between the core city and surrounding cities. At the same time, northwest increase the interconnection between the growth poles as well as the growth pole and the East Central growth poles. Silk Road economic infrastructure interconnection band basis, northwest should focus on the construction and improvement of a major thoroughfare connecting the eastern part and northwest China, Northwest connecting the southwest region, and the channel neighboring countries. Northwest should create a good business environment and innovative environment, and growth poles development need pilot enterprises and industrial development, which need a favorable institutional environment, policy environment, financial environment and innovation culture. Therefore, northwest need promotion and cultivation concept of modern market economy, and eliminate the impact of the traditional concept of natural economy and planned economy and Give full play to the role of city business platform, relax government regulations, reduce transaction costs to stimulate entrepreneurial energy. The Government should improve preferential policies to support entrepreneurship, and encourage entrepreneurship and gradually form a government, social support entrepreneurship, a new atmosphere. New growth poles should make use of financial support, tax relief, means of venture capital, financial services policy, and small loan guarantees for SMEs, especially start-up enterprise development to provide a good business environment.

\subsection{Northwest regions uses information technology to promote new growth poles leaps and bounds development.}

With the rise of the Internet, new energy and things as the representative of the third industrial revolution, information technology is increasingly becoming an important driving force for regional development, but also become an important factor in widening regional disparities. The main initiative is to accelerate the development of information infrastructure in Northwest China, and the implementation of information infrastructure cover the whole project, and accelerate "broadband, broadcasting, communication" information infrastructure transformation and upgrading, and enhance network coverage, the telecommunications network, radio and television networks, Internet, wireless networks and "multi-network integration." In the Guanzhong area where has good manufacturing basis for the information technology development, northwest should speed up the transform and upgrade the manufacturing sector, and implement "Internet +" action plan to promote the combination of mobile Internet, cloud computing, big data, networking and modern manufacturing industry and promote digital, networked, intelligent manufacturing, and promote the development of electronic commerce, industrial Internet and Internet banking, and the integration and development of manufacturing and producer services. In Xi'an, Yinchuan, Xining, Urumqi and other cities, it promotes the pilot of wisdom city," digital city", "smart city" and other major construction projects, and promote a new generation of innovative applications of information technology, networking, cloud computing, big data, etc. to achieve social development and economic deep integration. New growth poles should accelerate information-aware and intelligent application integration in social security, social management, health care, education, culture, health and other social areas, and build smart city management platform and support public service system to improve the effectiveness of urban management and public service Level (Wei Houkai, 2015).

\section{Reference}

Bai, Y. X. (2010). Technology Special Zone the difficulties and changes in the western region in Xi'an [J]. The Great Western Development, 4.

Guo, X. B. (2011). Development Economics [M] Beijing: Higher Education Press, 2011.

Zhang, X. L. (2013). China Regional Economic Development Report (2013)- Rise and coordination development of China's urban agglomeration [M] Beijing: People's Publishing House, 2013.

Wei, H. K. (2011).regional policy of China: Review and Prospect [M] Beijing: Economic Management Publishing House.

Wei, H. K., \& Zhao, Y. (2014). Strategic evaluation and policy suggestions for the further implementation of the western development [J]. Development and Research, 1 .

Wei, H. K. (2015). Thirteenth five-year plan" in West china [M] Beijing: Economic Management Publishing House.

\section{(c) $\mathrm{EY}$}

This work is licensed under a Creative Commons Attribution 3.0 License. 